\title{
Variability in Cerebral Oxygen Delivery Is Reduced in Premature Neonates Exposed to Chorioamnionitis
}

\author{
TOBY D. YANOWITZ, DOUGLAS M. POTTER, A'DELBERT BOWEN, ROBYN W. BAKER, AND JAMES M. ROBERTS
}

\begin{abstract}
Department of Pediatrics [T.D.Y., R.W.B.], Department of Obstetrics, Gynecology and Reproductive Sciences [J.M.R.], Department of Radiology [A.D.B], University of Pittsburgh School of Medicine, Pittsburgh, Pennsylvania 15213; Department of Biostatistics [D.M.P.], University of Pittsburgh, Pittsburgh, Pennsylvania 15213
\end{abstract}

\begin{abstract}
Premature infants exposed to chorioamnionitis are at increased risk for periventricular leukomalacia (PVL) and intraventricular hemorrhage (IVH), lesions that may result from inflammation and/or fluctuations in cerebral blood flow. The effect of chorioamnionitis on near-infrared spectroscopy (NIRS) measures of cerebral oxygen delivery has not been evaluated previously. Forty-nine infants born at 25-31 6/7 wk gestation underwent NIRS examination on $\mathrm{d} 1,2,3$, and 7 of life. Variability in NIRS tracings was analyzed by partitioning each tracing into three components: long-term, intermediate, and short-term variability; the latter two components were analyzed. Chorioamnionitis-exposed infants manifest reduced intermediate variability in cerebral oxygenated and deoxygenated $\mathrm{Hb}$ but not total $\mathrm{Hb}$. Infants with severe IVH/PVL had the lowest intermediate variability on $\mathrm{d} 1$. Short-term variability was similar between chorioamnionitis-exposed and unexposed infants, and between infants with versus without severe IVH or PVL. We conclude that intermediate-term variability in NIRS cerebral oxygen delivery is reduced in chorioamnionitis-exposed infants. We speculate that intermediate variability represents the important time frame for evaluating the pathogenesis of perinatal brain injury. Further studies are needed to determine how these findings relate to cerebral blood flow autoregulation and oxygen utilization in premature infants. (Pediatr Res 59: 299-304, 2006)
\end{abstract}

$\mathrm{C}$ horioamnionitis is perhaps the most common cause of premature delivery. Recent epidemiologic and clinical investigations indicate that premature infants who are exposed to chorioamnionitis are at increased risk for developing IVH (1), PVL (1,2), and cerebral palsy (2-4). The etiology of the white matter injury in chorioamnionitis-exposed infants remains uncertain but likely involves some component of ischemic $(5-8)$ and/or inflammatory $(9,10)$ damage to the developing oligodendroglia. It has been demonstrated that preterm infants who develop IVH have fluctuations in Doppler-derived cerebral blood flow velocities (11). With the application of NIRS, it became evident that infants with both IVH and PVL have fluctuations in cerebral oxygen delivery (12) that correlate with fluctuations in blood pressure and indicate impaired

Received April 19, 2005; accepted September 7, 2005.

Correspondence: Toby Debra Yanowitz, M.D., Department of Pediatrics, MageeWomens Hospital, 300 Halket St., Pittsburgh, PA 15217; e-mail: tyanowitz@mail. magee.edu

Supported by National Institutes of Health grant 1 K23 HD01317-01 and a grant from the Crown Center for Research on Women and Newborn Health.

DOI: 10.1203/01.pdr.0000196738.03171.f1 cerebral autoregulatory ability (11). The relationship between variability in NIRS measures of cerebral oxygen delivery and exposure to chorioamnionitis has not been evaluated previously.

The overall objective of this investigation was to determine the variability among NIRS measures of cerebral oxygen delivery in premature infants exposed and unexposed to chorioamnionitis. We first devised a method that would allow us to assess both intermediate and short-term variability in NIRS measures of cerebral oxygenated, deoxygenated, and total $\mathrm{Hb}$. Next, we tested the hypothesis that variability decreases with increasing gestational and postnatal age, as the risk of IVH and PVL abate. Finally, we compared variability in NIRS measures of cerebral oxygen delivery between infants exposed and unexposed to chorioamnionitis, and between infants with and without severe IVH/PVL.

\section{METHODS}

This study was approved by the Institutional Review Boards of MageeWomens Hospital and the University of Pittsburgh. Written, informed consent was obtained from parents of all subjects.

Singleton infants born at $250 / 7$ to $316 / 7$ wk gestation were recruited within the first $12 \mathrm{~h}$ of life. Exclusion criteria included congenital anomalies of the brain, heart, and kidneys; a history of hydrops fetalis; growth retardation (birth weight $<5$ th percentile for gestational age); respiratory failure (arterial $\mathrm{pH}<7.15, \mathrm{PaCO}_{2}>70, \mathrm{PaO}_{2}<40$ ); and significant anemia (hematocrit $<30 \%$ ).

Infants were stabilized by the pediatric house staff and attending neonatologist. Care was not altered for study purposes. NIRS examinations were performed shortly after enrollment, after 24 and $48 \mathrm{~h}$, and on d 7 of life. Because indomethacin decreases cerebral blood flow velocities $(13,14)$ for up to $2 \mathrm{~h}$ (13), infants receiving indomethacin were examined either before or more than $4 \mathrm{~h}$ after indomethacin administration.

Noninvasive measurements of heart rate, oxygen saturation, and blood pressure (BP) were made at the start of the study. Inasmuch as not all infants had indwelling arterial catheters, oscillometric mean BP (Dynamap; Critikon Inc., Tampa, FL), which correlates well with intra-arterial mean BP (15), was used for all infants.

NIRS. NIRO 300 (Hamamatsu, Japan) optodes were placed on the infant's forehead with the transmitting optode $1-2 \mathrm{~cm}$ left of midline and the receiving optode $4 \mathrm{~cm}$ laterally. Optodes were secured in a black plastic holder provided by Hamamatsu and affixed to the forehead with Webril undercast padding (Kendall Co., Mansfield, MA). The infant's head was then covered with an investigator-designed hat containing light-blocking black photographic plastic. If the infant's condition allowed, phototherapy was discontinued during monitoring.

Abbreviations: IVH, intraventricular hemorrhage; NIRS, near-infrared spectroscopy; PVL, periventricular leukomalacia 
A 4-cm path length and a 2-s sampling time were selected during the set-up procedure. Changes in oxygenated, deoxygenated, and total $\mathrm{Hb}$ were recorded for approximately $120 \mathrm{~min}$ on each study day, and the data stored in real-time on a portable computer. Attempts were made to limit interventions during this time. All spontaneous clinical events and necessary interventions were recorded on a bedside flow sheet and digitally time-stamped on the NIRS tracing by the research assistant.

Diagnosis of chorioamnionitis. Chorioamnionitis was diagnosed on placental histology by a pathologist unaware of the infant's clinical course and NIRS findings using criteria adapted from the Perinatal Section of the Society for Pediatric Pathology (16). Thus, chorioamnionitis was defined as the presence of neutrophils in the fibrous amnion and/or chorion (irrespective of severity or grade) or the presence of fetal vessel inflammation [chorionic vasculitis (intramural polymorphonuclear cells in the chorionic vessels), umbilical phlebitis (intramural polymorphonuclear cells in the umbilical vein), or umbilical vasculitis of one or two arteries].

Cranial ultrasound findings. Each infant underwent at least two cranial ultrasounds: the first before $72 \mathrm{~h}$ and the second around $14 \mathrm{~d}$ of life. Subsequent ultrasounds were at the discretion of the attending neonatologist. Ultrasounds were interpreted by a single pediatric radiologist and scored as PVL, IVH, or normal. PVL was defined as symmetric or asymmetric bilateral echolucent cysts $>2 \mathrm{~mm}$ in diameter occurring a) in the coronal projection, at the external angles of the lateral ventricles in the peritrigonal region and $b$ ) on the parasagittal projection, either diffusely distributed in the periventricular white matter or localized to regions adjacent to the trigone of the lateral ventricles, the frontal horn at the level of the foramen of Monro, or both (17). IVH was defined as by Papile et al. (18) and the highest grade bleed used for analysis.

Clinical data. Demographics, physiologic variables $\left(\mathrm{pH}, \mathrm{PaCO}_{2}\right.$, and $\mathrm{PaO}_{2}$, complete blood count, and differential), ventilator settings, drug administration, and blood culture results were recorded from the infant's chart after the hemodynamic studies were completed. Risk factors for premature delivery and drugs administered in the perinatal period were recorded from the maternal chart.

Statistical analysis. Clinical data were analyzed using the Wilcoxon rank sum test, Mann-Whitney, $\chi^{2}$ analysis, or Fisher's exact test, as appropriate.

NIRS data were analyzed as follows. First, the raw time series for each variable (oxygenated, deoxygenated, and total $\mathrm{Hb}$ ) from each baby on each study day was graphed in Excel (Microsoft, Redmond, WA). Segments containing obvious artifact were removed manually. Artifact was defined when the distance between two consecutive data points was $>3$ SD of the observed distribution of the distances between consecutive points, or when the NIRO 300 software displayed error messages. When the segments removed were short $(<4$ data points) and surrounding data points were of similar magnitude, the effect on the time series was ignored. When the segments containing apparent artifact were long, the artifact was removed and the time series split into two. Time segments were always split where infant movement resulted in "shift" of the baseline. For each infant day, all artifact-free time series of at least $750 \mathrm{~s}$ were analyzed.
Robust locally weighted linear regression (19) was used as a digital filter to smooth and partition the data for each variable on each day. The data were partitioned into three components: the long-term drift (smoothed over a 750-s window); the intermediate-term component, I (obtained by subtracting the drift and smoothing within a 100-s window); and the short-term component, $\mathrm{S}$ (obtained by subtracting both I and the drift). Our analysis highlights variation on the intermediate and short-term scale, and ignores the slow drift, whose time scale is unlikely to be related to autoregulatory capability. Thus, intermediate-term variability $\left(\operatorname{Var}_{\mathrm{I}}\right)$ and short-term variability $\left(\operatorname{Var}_{\mathrm{S}}\right)$ were defined as the standard deviations of the I and S components, respectively. When more than one time series was available for a given day, variance was calculated as an average, weighted by the length of each time series. Thus, $\operatorname{Var}_{\mathrm{I}}$ and $\mathrm{Var}_{\mathrm{S}}$ were calculated for oxygenated, deoxygenated, and total $\mathrm{Hb}$ for each baby on each study day.

The Wilcoxon signed rank test was used to assess the effect of postnatal age by comparing values from $\mathrm{d} 1$ to $\mathrm{d} 7$. The Spearman correlation was used to determine whether between-baby differences persisted from $\mathrm{d} 1$ to $\mathrm{d} 7$.

Friedman's test of equivalence indicated that neither $\operatorname{Var}_{\mathrm{I}}$ nor $\mathrm{Var}_{\mathrm{S}}$ differed over the first $3 \mathrm{~d}$ of life. Thus, a pooled variance was computed from the individual variances on $\mathrm{d} 1,2$, and 3 , weighted by the length of the time segments. The Spearman test was then used to assess the relationship between gestational age and variability.

The effect of chorioamnionitis was analyzed using the Wilcoxon rank sum test, first for all 4 study days, and then for individual days. In the former case, the variable "day" was used as the stratification variable for the Wilcoxon test, using one stratum per measurement day. The test was evaluated by permuting subject identification labels simultaneously for the $4 \mathrm{~d}$. Subsequently, a regression analysis was performed using the pooled data from d 1-3 and including the clinical factors gestational age, receipt of antenatal steroid, respiratory distress syndrome (or mechanical ventilation), severe IVH or PVL, initial hematocrit, and $\mathrm{pH}$.

NIRS measures are presented as $\Delta$ concentration ( $\Delta$ micromol/L). Normally distributed data are presented as mean \pm SD. Results for data that deviate from normality are given as median (Q1-Q3). Results were considered significant when $p<0.05$.

\section{RESULTS}

\section{Demographic and Clinical Characteristics of Subjects} Forty-nine babies were studied, 24 of whom were exposed to chorioamnionitis. Demographic and clinical characteristics of these infants are given in Table 1. The cardiorespiratory characteristics of the subjects are given in Table 2. Thirteen chorioamnionitis-exposed and 10 unexposed infants had a grade I IVH. Two infants in each group had a grade II IVH and one chorioamnionitis-exposed infant had a grade IV IVH.

Table 1. Demographic and clinical characteristics of infants

\begin{tabular}{|c|c|c|c|}
\hline & Chorio-exposed & Chorio-unexposed & $p$ Value \\
\hline Birth weight $(\mathrm{g}$, mean $\pm \mathrm{SD})$ & $1219 \pm 279$ & $1324 \pm 397$ & 0.3 \\
\hline Gestational age (wk) & $28(27-29.75)$ & $29(28-30)$ & 0.09 \\
\hline Gender ( $\%$ male $)$ & 58 & 63 & 0.7 \\
\hline Apgar at $1 \mathrm{~min}$ & $6(5-8)$ & $6(5-8)$ & 0.7 \\
\hline Apgar at $5 \mathrm{~min}$ & $8(7.25-9)$ & $8(7-9)$ & 0.4 \\
\hline Umbilical arterial $\mathrm{pH}$ & $7.285(7.245-7.335)$ & $7.290(7.22-7.35)$ & 0.9 \\
\hline Epinephrine at delivery [no. (\%)] & $0(0)$ & $0(0)$ & NS \\
\hline Early volume resuscitation [no. $(\%)]$ & $9(38)$ & $8(32)$ & 0.763 \\
\hline Respiratory distress syndrome & $14(58)$ & $13(52)$ & 0.656 \\
\hline Patent ductus arteriosus & $7(29)$ & $5(20)$ & 0.455 \\
\hline Arterial $\mathrm{pH}$ before study & $7.36(7.33-7.39)$ & $7.365(7.285-7.4)$ & 0.6 \\
\hline $\mathrm{Hb}$ on admission & $14.6(13.9-18.5)$ & $16.2(13.7-17.3)$ & 0.042 \\
\hline
\end{tabular}

* Seven-day antibiotic course.

Values: [median (Q1-Q3)], unless otherwise indicated 
Table 2. Cardiorespiratory characteristics on each study day

\begin{tabular}{|c|c|c|c|c|c|}
\hline & & Day 1 & Day 2 & Day 3 & Day 7 \\
\hline \multirow{2}{*}{$\begin{array}{l}\text { Mean arterial blood pressure } \\
(\mathrm{mm} \mathrm{Hg}, \text { mean } \pm \mathrm{SD})\end{array}$} & Chorio $(+)$ & $43.6 \pm 8.9$ & $42.5 \pm 8.4$ & $44.5 \pm 6.8$ & $42.9 \pm 7.5$ \\
\hline & Chorio $(-)$ & $42.1 \pm 11.4$ & $43.5 \pm 8.8$ & $41.4 \pm 6.0$ & $43.9 \pm 10.6$ \\
\hline \multirow[t]{2}{*}{ Vasopressor support } & Chorio $(+)$ & $2(8)$ & $3(13)$ & $2(8)$ & $0(0)$ \\
\hline & Chorio (-) & $2(8)$ & $1(4)$ & $0(0)$ & $0(0)$ \\
\hline \multirow[t]{2}{*}{ Indomethacin } & Chorio $(+)$ & $1(4)$ & $4(17)$ & $5(21)$ & $0(0)$ \\
\hline & Chorio $(-)$ & $3(12)$ & $4(16)$ & $1(4)$ & $0(0)$ \\
\hline \multirow[t]{2}{*}{ CPAP } & Chorio $(+)$ & $3(13)$ & $1(4)$ & $1(4)$ & $2(8)$ \\
\hline & Chorio $(-)$ & $1(4)$ & $3(12)$ & $2(8)$ & $3(12)$ \\
\hline \multirow[t]{2}{*}{ Ventilation } & Chorio $(+)$ & $14(58)$ & $10(42)$ & $7(29)$ & $4(17)$ \\
\hline & Chorio (-) & $11(44)$ & $5(20)$ & $5(20)$ & $1(4)$ \\
\hline \multirow[t]{2}{*}{ Surfactant } & Chorio $(+)$ & $14(58)$ & $6(25)$ & $0(0)$ & $0(0)$ \\
\hline & Chorio $(-)$ & $10(40)$ & $3(12)$ & $0(0)$ & $0(0)$ \\
\hline
\end{tabular}

Values given as number (\%), unless otherwise indicated.

CPAP, continuous positive airway pressure.

Two infants (4\%) had cystic PVL. Both of these infants had been exposed to chorioamnionitis.

Effect of postnatal age. Figure 1 represents a typical NIRS tracing and the manner in which it was broken down into its component parts. $\operatorname{Var}_{I}$ and $\operatorname{Var}_{S}$ were nonnormally distributed for all three NIRS measures (oxygenated, deoxygenated, and total $\mathrm{Hb}$ ). The median and ranges for these variables on each day are given in Table 3. There was no systematic effect of postnatal age on either $\operatorname{Var}_{\mathrm{I}}$ or $\operatorname{Var}_{\mathrm{S}}$ in either exposure group, or in the combined cohort.

Effect of gestational age. Variability in NIRS measures of oxygenated and deoxygenated $\mathrm{Hb}$ did not correlate with gestational age. $\operatorname{Var}_{\mathrm{I}}$ for total $\mathrm{Hb}$ was weakly correlated with increasing gestational age; $\rho=0.317(p<0.03)$. $\operatorname{Var}_{\mathrm{S}} \operatorname{did}$ not change as gestation advanced.

Effect of chorioamnionitis. Chorioamnionitis-exposed infants had reduced intermediate variability for both oxygenated and deoxygenated $\mathrm{Hb}$ (Fig. $2, p<0.05$ ). On post hoc analysis, $\operatorname{Var}_{\mathrm{I}}$ for oxygenated $\mathrm{Hb}$ was lower among exposed compared with unexposed infants on $\mathrm{d} 2$ (4.3 versus 5.9, respectively, $p$
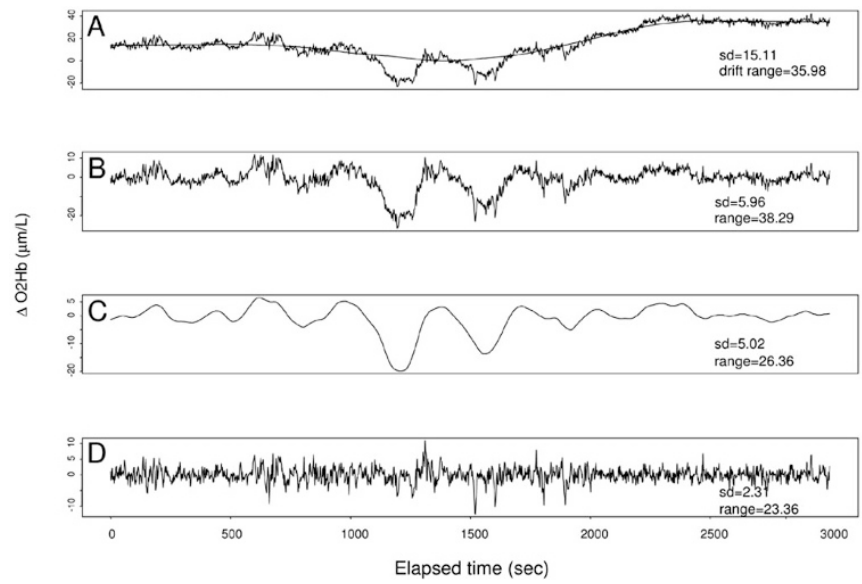

Figure 1. Statistical analysis of NIRS tracing for oxygenated $\mathrm{Hb}$ for a $26 \mathrm{wk}$ infant (743 g) on d 2. (A) Raw data with drift. Drift is calculated by smoothing over a 750-s window. $(B)$ The drift has been removed. $(C)$ Data are smoothed within a 100 -s window to obtain the intermediate component. Intermediate variability is calculated as the SD of this component. (D) The drift and intermediate component are subtracted out, leaving the short-term component. The short-term variability is calculated as the SD of this short-term component.
$=0.004)$ and $\mathrm{d} 3$ (3.6 versus 5.1, $p=0.0096$ ). $\operatorname{Var}_{\mathrm{I}}$ for deoxygenated $\mathrm{Hb}$ was lower among the chorioamnionitisexposed infants on $\mathrm{d} 1(2.5$ versus $3.4, p=0.028)$ and showed a strong tendency to be lower on $\mathrm{d} 2$ (3.1 versus $4.0, p=0.11)$ and $\mathrm{d} 3$ (2.2 versus $3.2, p=0.057)$. $\operatorname{Var}_{\mathrm{I}}$ for total $\mathrm{Hb}$ did not differ between exposed and unexposed infants. $\operatorname{Var}_{\mathrm{S}}$ was not different between exposed and unexposed infants for any of the NIRS variables studied.

NIRS variability among infants with severe IVH and PVL. Intermediate variability for oxygenated, deoxygenated, and total $\mathrm{Hb}$ were lower among the three infants with either grade IV IVH or cystic PVL than among infants without severe brain injury on d 1 (Fig. 3; $p=0.013,0.0019$, and 0.047, respectively), but not on subsequent study days.

Evaluation of confounders: regression model. Because the three infants with severe IVH or PVL were all exposed to chorioamnionitis, a regression was performed in which both chorioamnionitis and severe IVH/PVL were included the model, along with the following covariates: receipt of antenatal steroid, the presence of respiratory distress syndrome or the need for mechanical ventilation, initial $\mathrm{Hb}$, initial $\mathrm{pH}$, and gestational age. A second regression was then performed using only the covariates with a $p$ value $<0.5$ in the first regression. The outcome variable in each model was $\mathrm{Var}_{\mathrm{I}}$, pooled over d 1-3. In these regression models, chorioamnionitis was the only factor that predicted $\operatorname{Var}_{\mathrm{I}}$ for oxygenated $(p=0.0048) \mathrm{Hb}$. Chorioamnionitis $(p=0.0385)$ and antenatal steroid $(p=0.0172)$ were significant predictors for intermediate variability of deoxygenated $\mathrm{Hb}$ in the first regression; in the limited model, receipt of antenatal steroid $(p=0.0136)$ remained significant, whereas chorioamnionitis $(p=0.0646)$ did not, at our chosen level of significance. The only factor found to predict $\mathrm{Var}_{\mathrm{I}}$ for total $\mathrm{Hb}$ was the presence/absence of respiratory distress syndrome $(p=0.0064)$.

\section{DISCUSSION}

We have devised a method to quantify the variability in cerebral oxygen delivery as measured by NIRS and have used our method to evaluate differences between chorioamnionitisexposed and unexposed premature infants. We found that intermediate variability was reduced in chorioamnionitis- 
Table 3. NIRS variability by postnatal age and exposure to chorioamnionitis

\begin{tabular}{|c|c|c|c|c|c|c|}
\hline & & & Day 1 & Day 2 & Day 3 & Day 7 \\
\hline \multirow[t]{5}{*}{$\operatorname{Var}_{I}$} & $\mathrm{O}_{2} \mathrm{Hb}$ & Chorio $(+)$ & $3.72(2.64-4.91)$ & $4.28(3.15-5.52)$ & $3.57(3.03-5.89)$ & $3.76(3.17-5.12)$ \\
\hline & & Chorio (-) & $4.41(3.19-5.83)$ & $5.98(4.39-7.90)$ & $5.08(4.28-7.24)$ & $4.18(3.71-7.4)$ \\
\hline & $\mathrm{HHb}$ & Chorio $(+)$ & $2.55(1.72-3.50)$ & $3.15(2.89-4.48)$ & $2.25(1.75-4.45)$ & $3.48(1.95-4.98)$ \\
\hline & $\mathrm{tHb}$ & Chorio $(+)$ & $3.63(2.84-5.98)$ & $4.44(3.21-6.03)$ & $3.77(2.57-4.70)$ & $4.54(3.44-5.47)$ \\
\hline & & Chorio (-) & $3.83((2.97-5.73)$ & $4.54(2.83-6.38)$ & $4.35(3.49-5.49)$ & $4.14(3.15-5.53)$ \\
\hline \multirow[t]{4}{*}{$\operatorname{Var}_{\mathrm{S}}$} & $\mathrm{O}_{2} \mathrm{Hb}$ & Chorio (+) & $5.25(2.83-9.01)$ & $5.06(3.23-8.38)$ & $3.52(2.87-5.67)$ & $4.91(4.22-8.88)$ \\
\hline & & Chorio $(-)$ & $2.57(1.91-3.86)$ & $2.75(2.37-3.75)$ & $2.39(1.88-3.27)$ & $3.22(2.33-3.99)$ \\
\hline & $\mathrm{tHb}$ & Chorio $(+)$ & $6.19(3.68-13.75)$ & $6.89(3.83-12.51)$ & $4.49(3.31-7.09)$ & $6.83(5.32-10.73)$ \\
\hline & & Chorio (-) & $5.69(3.79-9.67)$ & $6.80(3.43-8.78)$ & $5.11(4.26-7.02)$ & $5.77(4.35-9.62)$ \\
\hline
\end{tabular}

$\operatorname{Var}_{I}$ and $\operatorname{Var}_{S}$, intermediate and short-term variability, respectively. $\mathrm{O}_{2} \mathrm{Hb}, \mathrm{HHb}$, tHb: oxygenated, deoxygenated, and total hemoglobin, respectively. Values: median $(\mathrm{Q} 1-\mathrm{Q} 3)$; units are $\mathrm{mm} / \mathrm{L}$.

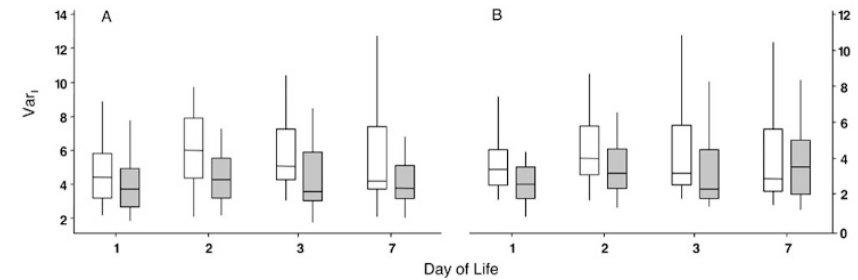

Figure 2. Intermediate variability for both oxygenated $(A)$ and deoxygenated (B) $\mathrm{Hb}$ was lower among the 24 chorioamnionitis-exposed (shaded bars) compared with the 25 unexposed (open bars) infants. On post hoc analysis, the differences in variability for oxygenated $\mathrm{Hb}$ were greatest on $\mathrm{d} 2(p=$ $0.004)$ and $\mathrm{d} 3(p=0.0096)$. $\operatorname{Var}_{\mathrm{I}}$ for deoxygenated $\mathrm{Hb}$ was lowest on $\mathrm{d} 1$ $(p=0.028)$, but showed a strong tendency to be lower on $\mathrm{d} 2(p=0.11)$ and d $3(p=0.057)$.

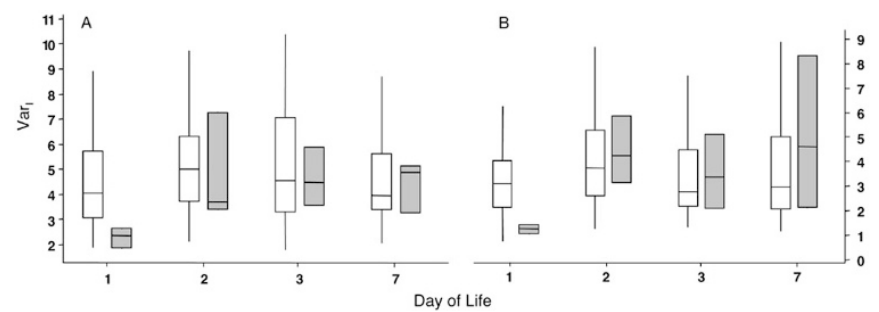

Figure 3. Intermediate variability for both oxygenated $(A)$ and deoxygenated (B) Hb was lower among the three infants with (shaded bars) compared with the 46 infants without (open bars) severe IVH/PVL on d 1 ( $p=0.0127$ and $p=0.0019$, respectively).

exposed infants and was markedly reduced in infants with grade IV IVH or PVL.

Premature newborns exposed to chorioamnionitis manifest a systemic inflammatory response syndrome (20-22) characterized by elevated proinflammatory cytokine concentrations $(23,24)$ and an increased propensity for adverse outcomes (25), including respiratory distress syndrome, bronchopulmonary dysplasia, necrotizing enterocolitis, IVH, and PVL. Despite the prevalence of chorioamnionitis in pregnancies that deliver before $32 \mathrm{wk}$, there is a paucity of information regarding its hemodynamic effects on the newborn. We have shown previously that BP is lower among chorioamnionitis-exposed infants, both within the first hours after birth (24) and persisting for the entire first week of life (26). Additionally, BP in the first hours after birth correlates inversely with cord blood IL-6 concentration (24). In the previous investigations we did not find gross disturbances in middle cerebral artery Doppler blood flow velocity and did not investigate variability in this measure.

In the current study, we used NIRS to evaluate variability in cerebral oxygenation among infants exposed and unexposed to chorioamnionitis and at risk of brain injury from IVH and PVL. Variability is an intrinsic characteristic of all biologic systems. The degree of variability in NIRS that is pathologic has not yet been determined. By partitioning the NIRS data into three components (short-, intermediate-, and long-term) we were able to evaluate the fluctuations in oxygenated, deoxygenated, and total $\mathrm{Hb}$ over three distinct time scales.

Short-term variability, $\operatorname{Var}_{\mathrm{S}}$, most likely represents the noise in the NIRS signal, which may be intrinsic to the NIRO 300 spectroscoper or may be related to the sampling frequency. We cannot exclude the possibility that $\operatorname{Var}_{\mathrm{S}}$ is caused by small side-to-side movements of an infant's head briefly disrupting probe-to-skin contact, inasmuch as we chose not to use adhesive glue on the fragile skin of these immature newborns. Because $\operatorname{Var}_{S}$ did not change with either gestational or postnatal age, and was similar among chorioamnionitis-exposed and -unexposed infants, the contribution of this short-term component to physiologically significant variability is likely to be small.

Intermediate term variability, $\operatorname{Var}_{\mathrm{I}}$, occurred over the time scale that may represent an infant's ability to autoregulate cerebral blood flow, and for which changes in oxygen utilization and extraction can be detected. This is the frequency to which major physiologic importance has been attributed (27). We had hypothesized that $\operatorname{Var}_{\text {I }}$ for all NIRS parameters would be increased in infants of younger gestational and postnatal age who are statistically at higher risk of IVH. In fact, we found that intermediate term variability for all NIRS parameters was not influenced by gestational or postnatal age, and was lowest among infants with severe brain injury on $\mathrm{d} 1$ of life. This finding is reminiscent of the "stability" of oxygen delivery described for term infants with perinatal asphyxia (28), in whom oxygen extraction is very low. Infants exposed to chorioamnionitis had lower $\operatorname{Var}_{\text {I }}$ for oxygenated and deoxygenated $\mathrm{Hb}$, indicating that these at-risk infants may have altered cerebral energy metabolism and less variable oxygen extraction, irrespective of whether absolute oxygen utilization 
is increased or decreased. Further studies evaluating variability among more specific indicators of cerebral metabolism (e.g. cytochrome $\mathrm{aa}_{3}$ ) and oxygen saturation [e.g. tissue oxygenation index (TOI)] may help confirm this theory.

Although we made all attempts to monitor infants during quiet times and excluded tracings that were obtained during active interventions, it is possible that infant movement affected $\operatorname{Var}_{\mathrm{I}}$. Instances when oxygenated $\mathrm{Hb}$ decreased and deoxygenated $\mathrm{Hb}$ increased during activity were noted. These were equally frequent in chorioamnionitis-exposed and -unexposed infants. Quantification of the degree of change in the NIRS parameters with movement will help elucidate whether the cellular oxygen demand with activity differs for chorioamnionitis-exposed and -unexposed infants.

It is interesting that $\operatorname{Var}_{\mathrm{I}}$ for total $\mathrm{Hb}$ did not change with chorioamnionitis exposure and that, in regression analysis, $\operatorname{Var}_{\mathrm{I}}$ for total $\mathrm{Hb}$ was predicted only by the presence of respiratory distress syndrome. Changes in total $\mathrm{Hb}$ should parallel changes in cerebral blood flow, and are affected primarily by changes in arterial oxygen content, $\mathrm{PaCO}_{2}$ and $\mathrm{BP}$ (in infants who lack autoregulatory capacity). In this respect, these findings resemble the Doppler data of Perlman et al. (11), in which parallel fluctuations in systemic BP and middle cerebral artery blood flow velocity were found in infants with respiratory distress syndrome. Because we did not measure BP continuously, we can only speculate that our observed variability indicates impaired autoregulatory capacity.

The analysis that we presented ignores the slow component of variability. This "drift" may represent the slow equilibration in cerebral oxygen utilization that occurs in infants who are left alone for the study after being disturbed for routine care and the application of the NIRS probes. Such "drift" has been described (29). Given the slow nature of these changes, we do not believe they represent an important physiologic risk factor for brain injury in premature infants.

We placed the NIRS optodes $4 \mathrm{~cm}$ apart on the forehead yielding a depth of penetration of $1 \mathrm{~cm} \mathrm{(30).} \mathrm{In} \mathrm{premature}$ infants of 25-32 wk gestation, the brain cortical thickness ranges from 10 to $15 \mathrm{~mm}$ (31). Although we found no systematic effect of gestational age, it is possible that, with gestational age and increasing complexity of the gyration pattern, we were imaging gray rather than white matter. Premature infants with white matter injury characteristic of PVL have been found to have reduced gray matter volumes at term gestation (32). If indeed we imaged gray rather than white matter, our findings may indicate that the gray matter of chorioamnionitis-exposed infants is involved in the initial pathophysiologic process, rather than secondarily affected.

Cranial ultrasounds were obtained with the first $72 \mathrm{~h}$ and again on d 14 of life. Because the cysts characteristic of PVL can be transient, it is possible that some cases of PVL were missed. Although later ultrasounds may show ventriculomegaly in infants with white matter disease, such ultrasound findings will still miss up to 50\% (33) of infants who go on to develop cerebral palsy. We are currently performing neurodevelopmental follow-up on the study infants and hope to determine whether variability in NIRS measures of cerebral oxygenation in the first week of life can predict later developmental disabilities.

The relative roles of inflammation and hypoxia-ischemia in the pathogenesis of brain injury in premature infants remain uncertain. Although much literature supports a relationship between either PVL or cerebral palsy and chorioamnionitis exposure $(1-4,34)$ or cytokine elevations $(9,35)$, recent reports $(36,37)$ refute this association. The role of hypoxia-ischemia is equally unclear. The maturation-dependent vulnerability of oligodendroglial progenitors to hypoxia-ischemia (6) explains how selective reduction in white matter blood flow in the dog (8) and the human premature infant (7) can result in PVL. Although hypotension has been associated with severe IVH (38) and not with white matter injury (39), impaired autoregulation has been demonstrated for infants with both severe IVH and PVL (12). Our data suggest a complex relationship exists between perinatal inflammation and cerebral hemodynamics. Lower NIRS variability among chorioamnionitisexposed infants suggests that inflammation somehow alters either cerebrovascular responsiveness or cellular oxygen utilization. Whether this is pathogenic in producing brain injury or merely an epiphenomenon remains to be determined. Inasmuch as infants with grade IV IVH/PVL had the lowest Var , it is tempting to consider this reduction in variability as pathologic.

In summary, we have developed a technique for use in measuring the variability in cerebral oxygenation among premature infants using NIRS. The full implications of this variability are not known. However, applying this technique to more infants with IVH and PVL may help elucidate the mechanism of brain injury in chorioamnionitis-exposed infants.

\section{REFERENCES}

1. De Felice C, Toti P, Laurini RN, Stumpo M, Picciolini E, Todros T, Tanganelli P, Buonocore G, Bracci R 2001 Early neonatal brain injury in histologic chorioamnionitis. J Pediatr 138:101-104

2. Dammann O, Leviton A 1997 Maternal intrauterine infection, cytokines, and brain damage in the preterm newborn. Pediatr Res 42:1-8

3. Zupan V, Gonzalez P, Lacaze-Masmonteil T, Boithias C, d'Allest AM, Dehan M, Gabilan JC 1996 Periventricular leukomalacia: risk factors revisited. Dev Med Child Neurol 38:1061-1067

4. de Vries LS, Regev R, Dubowitz LM, Whitelaw A, Aber VR 1988 Perinatal risk factors for the development of extensive cystic leukomalacia. Am J Dis Child 142:732-735

5. Lou HC 1994 Hypoxic-hemodynamic pathogenesis of brain lesions in the newborn. Brain Dev 16:423-431

6. Back SA, Han BH, Luo NL, Chricton CA, Xanthoudakis S, Tam J, Arvin KL, Holtzman DM 2002 Selective vulnerability of late oligodendrocyte progenitors to hypoxia-ischemia. J Neurosci 22:455-463

7. Greisen G, Borch K 2001 White matter injury in the preterm neonate: the role of perfusion. Dev Neurosci 23:209-212

8. Young RS, Hernandez MJ, Yagel SK 1982 Selective reduction of blood flow to white matter during hypotension in newborn dogs: a possible mechanism of periventricular leukomalacia. Ann Neurol 12:445-448

9. Yoon BH, Romero R, Kim CJ, Koo JN, Choe G, Syn HC, Chi JG 1997 High expression of tumor necrosis factor-alpha and interleukin-6 in periventricular leukomalacia. Am J Obstet Gynecol 177:406-411

10. Noetzel MJ, Brunstrom JE 2001 The vulnerable oligodendrocyte: inflammatory observations on a cause of cerebral palsy. Neurology 56:1254-1255

11. Perlman JM, McMenamin JB, Volpe JJ 1983 Fluctuating cerebral blood-flow velocity in respiratory-distress syndrome. Relation to the development of intraventricular hemorrhage. N Engl J Med 309:204-209

12. Tsuji M, Saul JP, du Plessis A, Eichenwald E, Sobh J, Crocker R, Volpe JJ 2000 Cerebral intravascular oxygenation correlates with mean arterial pressure in critically ill premature infants. Pediatrics 106:625-632

13. Van Bel F, Van de Bor M, Stijnen T, Baan J, Ruys JH 1989 Cerebral blood flow 
velocity changes in preterm infants after a single dose of indomethacin: duration of its effect. Pediatrics 84:802-807

14. Yanowitz TD, Baker RW, Sobchak Brozanski B 2003 Prophylactic indomethacin reduces grades III and IV intraventricular hemorrhages when compared to early indomethacin treatment of a patent ductus arteriosus. J Perinatol 23:317-322

15. Park MK, Menard SM 1987 Accuracy of blood pressure measurement by Dinamap monitor in infants and children. Pediatrics 79:907-914

16. Redline RW, Faye-Petersen O, Heller D, Qureshi F, Savell V, Vogler C; 2003 Amniotic infection syndrome: nosology and reproducibility of placental reaction patterns. Pediatr Dev Pathol 6:435-448

17. Volpe JJ 2001 Hypoxic-ischemic encephalopathy: clinical aspects. In: Volpe JJ (ed) Neurology of the Newborn, W.B. Saunders, Philadelphia, pp 343-345

18. Papile LA, Burstein J, Burstein R, Koffler H 1978 Incidence and evolution of subependymal and intraventricular hemorrhage: a study of infants with birth weights less than 1,500 gm. J Pediatr 92:529-534

19. Cleveland WS 1979 Robust locally weighted regression and smoothing of scatterplots. J Am Stat Assoc 74:829-836

20. Gomez R, Romero R, Ghezzi F, Yoon BH, Mazor M, Berry SM 1998 The fetal inflammatory response syndrome. Am J Obstet Gynecol 179:194-202

21. Chaiworapongsa T, Romero R, Kim JC, Kim YM, Blackwell SC, Yoon BH, Gomez R 2002 Evidence for fetal involvement in the pathologic process of clinical chorioamnionitis. Am J Obstet Gynecol 186:1178-1182

22. Pacora P, Chaiworapongsa T, Maymon E, Kim YM, Gomez R, Yoon BH, Ghezzi F, Berry SM, Qureshi F, Jacques SM, Kim JC, Kadar N, Romero R 2002 Funisitis and chorionic vasculitis: the histological counterpart of the fetal inflammatory response syndrome. J Matern Fetal Neonatal Med 11:18-25

23. Yoon BH, Romero R, Kim CJ, Jun JK, Gomez R, Choi JH, Syn HC 1995 Amniotic fluid interleukin-6: a sensitive test for antenatal diagnosis of acute inflammatory lesions of preterm placenta and prediction of perinatal morbidity. Am J Obstet Gynecol 172:960-970

24. Yanowitz TD, Jordan JA, Gilmour CH, Towbin R, Bowen A, Roberts JM, Brozanski BS 2002 Hemodynamic disturbances in premature infants born after chorioamnionitis: association with cord blood cytokine concentrations. Pediatr Res 51:310-316

25. Gomez R, Romero R, Ghezzi F, Yoon BH, Mazor M, Berry SM 1998 The fetal inflammatory response syndrome. Am J Obstet Gynecol 179:194-202

26. Yanowitz TD, Baker RW, Roberts JM, Brozanski BS 2004 Low blood pressure among very-low-birth-weight infants with fetal vessel inflammation. J Perinatol 24:299-304
27. Morren G, Naulaers G, Lemmerling P, Van Huffel S, Casaer P, Devlieger H 2003 Quantitation of the concordance between cerebral intravascular oxygenation and mean arterial blood pressure for the detection of impaired autoregulation. Adv Exp Med Biol 510:403-408

28. Pryds O, Greisen G, Lou H, Friis-Hansen B 1990 Vasoparalysis associated with brain damage in asphyxiated term infants. J Pediatr 117:119-125

29. Elwell C 1995 A Practical User's Guide to Near-Infrared Spectroscopy. UCL Reprographics, London

30. Villringer K, Minoshima S, Hock C, Obrig H, Ziegler S, Dirnagl U, Schwaiger M, Villringer A 1997 Assessment of local brain activation. A simultaneous PET and near-infrared spectroscopy study. Adv Exp Med Biol 413:149-153

31. England M 1988 Normal Development in the Central Nervous System. Wellcome Trust, London

32. Inder TE, Huppi PS, Warfield S, Kikinis R, Zientara GP, Barnes PD, Jolesz F, Volpe JJ 1999 Periventricular white matter injury in the premature infant is followed by reduced cerebral cortical gray matter volume at term. Ann Neurol 46:755-760

33. Pinto-Martin JA, Riolo S, Cnaan A, Holzman C, Susser MW, Paneth N 1995 Cranial ultrasound prediction of disabling and nondisabling cerebral palsy at age two in a low birth weight population. Pediatrics 95:249-254

34. Wu YW, Colford JM Jr 2000 Chorioamnionitis as a risk factor for cerebral palsy: a meta-analysis. JAMA 284:1417-1424

35. Leviton A 1993 Preterm birth and cerebral palsy: is tumor necrosis factor the missing link? Dev Med Child Neurol 35:553-558

36. Nelson KB, Grether JK, Dambrosia JM, Walsh E, Kohler S, Satyanarayana G, Nelson PG, Dickens BF, Phillips TM 2003 Neonatal cytokines and cerebral palsy in very preterm infants. Pediatr Res 53:600-607

37. Wood NS, Costeloe K, Gibson AT, Hennessy EM, Marlow N, Wilkinson AR; 2005 The EPICure study: associations and antecedents of neurological and developmental disability at 30 months of age following extremely preterm birth. Arch Dis Child Fetal Neonatal Ed 90:F134-F140

38. Bada HS, Korones SB, Perry EH, Arheart KL, Ray JD, Pourcyrous M, Magill HL, Runyan 3rd, W Somes GW, Clark FC, et al 1990 Mean arterial blood pressure changes in premature infants and those at risk for intraventricular hemorrhage. J Pediatr 117:607-614

39. Dammann O, Allred EN, Kuban KC, Van Marter LJ, Pagano M, Sanocka U, Leviton A; 2002 Systemic hypotension and white-matter damage in preterm infants. Dev Med Child Neurol 44:82-90 